\title{
The Neurophysins of the Pig
}

\author{
By L. O. Uttenthal, Y. Ishida and D. B. Hope \\ Department of Pharmacology, University of Oxford
}

(Received 21 August 1967)

Oxytocin and vasopressin are precipitated by salt from extracts of the posterior pituitary gland as a complex with a protein, which Acher, Manoussos \& Olivry (1955) termed neurophysin. In contrast with the evidence of van Dyke, Chow, Greep \& Rothen (1942), who isolated an apparently homogeneous protein of mol.wt. 30000 from fresh bovine tissue, later studies of the protein moiety of the complex revealed several components separable by starch-gel electrophoresis (Hope, Schacter \& Frankland, 1964). Electrophoresis of lysed bovine posterior-pituitary neurosecretory granules free from mitochondrial and lysosomal enzymes, however, demonstrated only two protein constituents (Dean \& Hope, 1966). As the components absent from neurosecretory granules could not be detected in other subcellular fractions, it was evident that the many constituents of neurophysin prepared by the method of Acher, Chauvet \& Olivry (1956) must have appeared during the isolation procedure. Dean, Hollenberg \& Hope (1967) studied the influence of $\mathrm{pH}$ on the catheptic activity present in extracts of acetone-dried bovine posterior-pituitary powder, and developed an extraction procedure whereby initial treatment of the powder with $0.1 \mathrm{~N}-\mathrm{HCl}$ at $\mathrm{pH} 1.5$ irreversibly destroys this activity. The resulting salt-precipitated protein was shown by starch-gel electrophoresis to consist of the two components found in the neurosecretory granules.

The demonstration of two native neurophysins in the ox has made it of interest to investigate the neurophysins of another species in which there are two posterior-pituitary hormones. This is the case in all vertebrates so far examined, except the lamprey (Acher, 1966). A convenient species to study is the domestic pig, from which fresh and acetone-dried glands are abundantly available, and which has the added interest that its vasopressin is [8-lysine]-vasopressin in contrast with the [8arginine]-vasopressin occurring in most other mammalian species. In the present investigation, the salt-precipitable proteins from acetone-dried porcine posterior-pituitary powder, extracted by a procedure designed to inactivate cathepsin, were studied by gel filtration and electrophoresis. Two major components of neurophysin were identified.

Methods. A sample (10g.) of acetone-dried powder of porcine posterior lobes (1-3i.u. of oxytocic activity/mg.) was extracted in $10 \mathrm{ml}$. of $\mathrm{N}-\mathrm{HCl}$ and $250 \mathrm{ml}$. of $0 \cdot 1 \mathrm{~N}-\mathrm{HCl}$ for $18 \mathrm{hr}$. at $4^{\circ}(\mathrm{pH} \mathrm{1.2})$. The insoluble material was removed by centrifugation, re-extracted in another $100 \mathrm{ml}$. of $0.1 \mathrm{~N}-\mathrm{HCl}$ and centrifuged; the supernatants were combined and their $\mathrm{pH}$ was adjusted to 3.9 with $4 \mathrm{~N}-\mathrm{NaOH}$. Then $\mathrm{NaCl}$ was added to bring the concentration to $80 \mathrm{~g} . / 1$. The precipitated protein was removed by centrifugation and dissolved in $100 \mathrm{ml}$. of distilled water with a few drops of acetic acid, dialysed against three changes of 61 . of distilled water for $18 \mathrm{hr}$. and freeze-dried. Gel filtration of the protein on fine-grade bead-type Sephadex G-25, G-50 and G-75 in 0.1 N-formic acid was carried out as described by Hollenberg \& Hope (1967). Zone electrophoresis was done in horizontal starch gels as described by Dean et al. (1967), and equilibrium dialysis was performed as described by Hollenberg \& Hope (1967).

Results and discussion. Gel filtration of the protein-hormone complex on Sephadex G-25 yielded a protein peak (detected by u.v. absorption at $257 \mathrm{~m} \mu$ ) free from hormonal activity emerging with the void volume, and a second peak containing both oxytocic and vasopressor activities. Unlike [8-arginine]-vasopressin, which is separated from oxytocin by filtration on Sephadex G-25 (Frankland, Hollenberg, Hope \& Schacter, 1966), [8-lysine]vasopressin is not appreciably separated from oxytocin. The protein fraction was recovered and submitted to gel filtration on Sephadex G-75. The first peak $(A)$ emerged with the void volume of the column $(120 \mathrm{ml}$.), indicating mol.wt. above 50000 . Then, between 250 and $350 \mathrm{ml}$. of eluent, a further two incompletely separated peaks ( $B$ and $C$ ) appeared, peak $C$ being slightly greater than peak $B$. Both peaks $B$ and $C$ were eluted at a volume lower than that for bovine neurophysins (Hollenberg \& Hope, 1967) on the same column. This suggests that their constituents have mol.wt. greater than 20000 , the value established for bovine neurophysins. The $E_{280} / E_{260}$ ratio was 0.93 across peak $B$, and 0.84 across peak $C$, though the latter ratio rose sharply to 1.2 at the trailing end of the peak. The low $E_{280} / E_{260}$ ratio is a characteristic of bovine neurophysins, and is also shown by peptide II, isolated from porcine pituitary glands by Friesen \& 


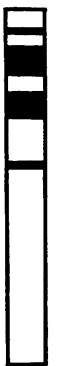

(1)

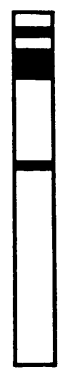

(2)

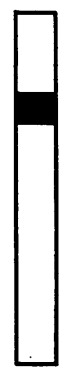

(3)

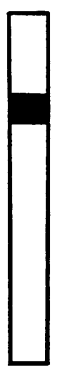

(4)

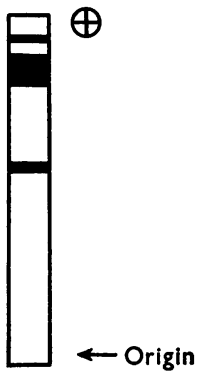

(5)
Fig. 1. Diagrammatic representation of starch-gel electrophoretograms of protein fractions eluted from Sephadex: (1) peak $B$ from Sephadex G-75; (2) peak $C$ from Sephadex G-75; (3) first peak obtained by filtration of material from peak $B$ through Sephadex G-50; (4) peak $B$ after recycling twice through Sephadex G-75; (5) peak $C$ after recycling twice through Sephadex G-75.

Astwood (1967). Of the protein recovered, $54 \%$ by weight was found in peak $A, 16 \%$ in peak $B$ and $18 \%$ in peak $C$.

When proteins from peaks $A, B$ and $C$ were submitted to electrophoresis, it was found that material from peak $A$ did not form distinct bands, but appeared as a continuous streak along the path of migration. The results for material from peaks $B$ and $C$ are shown in Fig. 1. It was evident that the material in peak $B$ contained a portion of the constituents of peak $C$, owing to the incomplete separation on Sephadex G-75. Material from peak $B$ was therefore placed on a column $(150 \mathrm{~cm} . \times 2 \mathrm{~cm}$.) of Sephadex G-50 and eluted with 0.1 N-formic acid. Two peaks were obtained: the first to be eluted was shown by electrophoresis to contain only the major constituent of peak $B$, whereas the second to be eluted contained the three components (one major, and two minor) of peak $C$. A similar separation was obtained by recycling pooled material from peaks $B$ and $C$ twice on a column $(112 \mathrm{~cm} . \times 3.9 \mathrm{~cm}$.) of Sephadex G-75. Thus peak $B$ represents a protein that appears as a single dense band on electrophoresis in the buffer system used, whereas peak $C$ represents a major component, faster moving than that of peak $B$, with traces of a fast-moving and a slow-moving contaminant.

Equilibrium-dialysis studies showed that the material from peak $A$ lacked the ability to bind either oxytocin or [8-lysine]-vasopressin. The single protein component of peak $B$, obtained pure by filtration through Sephadex G-50, was dialysed against sodium acetate buffer, $\mathrm{pH} 5.6$ and $I 0 \cdot 1$, containing $4 \cdot 8$ i.u. of oxytocin and $2 \cdot 8$ i.u. of [8-lysine]-vasopressin/ml. At equilibrium there was a 22.5-fold concentration ratio of oxytocin and a 20-fold concentration ratio of [8-lysine]-vasopressin between inner and outer compartments, the protein and the greater concentration of hormone being present in the inner compartment. A similar experiment performed on material from peak $C$, free of the protein from peak $B$, produced concentration ratios of $9 \cdot 3$ for oxytocin and 16.3 for [8-lysine]-vasopressin.

Preliminary amino acid analyses of the single protein from peak $B$ and the material from peak $C$ indicate that the two hormone-binding proteins are both rich in cystine (11.5-12.5\%), proline (8-9\%) and glutamic acid (13-18\%), and both contain methionine and histidine. This is very similar to the amino acid compositions of bovine neurophysins (Hollenberg \& Hope, 1967).

The finding of two cystine-rich proteins, which have the capacity to bind both oxytocin and [8-lysine]-vasopressin, in salt-precipitated proteins from an extract of acetone-dried procine posteriorpituitary powder is noteworthy in view of the demonstration of two neurophysins in the ox (Dean et al. 1967). Unlike the bovine neurophysins, which both have mol.wt. about 20000 , the two porcine neurophysins are separable on Sephadex G-75 and G-50, which suggests that they differ considerably in molecular weight; their elution volumes suggest that they have mol.wt. above 20000 . Ginsburg, Jayasena \& Thomas (1966) used ion-exchange chromatography to isolate a neurophysin from the pig. This protein appeared to have mol.wt. about 25000 , and, although it sedimented as a single peak in the analytical ultracentrifuge, its solubility in different concentrations of $\left(\mathrm{NH}_{4}\right)_{2} \mathrm{SO}_{4}$ solution indicated that it was not homogeneous.

The equilibrium dialysis studies carried out so far do not indicate any selective affinity of the two components for oxytocin or [8-lysine]-vasopressin. This poses the question of what significance the existence of two neurophysins is. Two physiological roles of neurophysins have been proposed: that they may be carriers of the peptide hormones, or that they may represent precursors, or the remains of precursors, of the hormones, which incidentally function as carriers. Could one neurophysin be the remains of the precursor of oxytocin, and the other be the remains of the precursor of vasopressin; and could each be associated with only one hormone in the secretory granules of the neurohypophysis, despite their lack of specific binding in vitro?

This work was supported by a research grant from the Medical Research Council. L.O.U. is grateful to the Medical Research Council for a Scholarship.

Acher, R. (1966). Angew. Chem. 5, 798.

Acher, R., Chauvet, J. \& Olivry, G. (1956). Biochim. biophys. Acta, 22, 421.

Acher, R., Manoussos, G. \& Olivry, G. (1955). Biochim. biophys. Acta, 16, 155. 
Dean, C. R., Hollenberg, M. D. \& Hope, D. B. (1967). Ginsburg, M., Jayasena, K. \& Thomas, P. J. (1966). J. Biochem.J. 104, 8c. Physiol. 184, 387.

Dean, C. R. \& Hope, D. B. (1966). Biochem. J. 101, Hollenberg, M. D. \& Hope, D. B. (1967). Biochem. J. 104, $17 \mathrm{P}$. 122.

Frankland, B. T. B., Hollenberg, M. D., Hope, D. B. \& Hope, D. B., Schacter, B. A. \& Frankland, B. T. B. (1964). Schacter, B. A. (1966). Brit. J. Pharmacol. 26, 502. Biochem.J. 93, 7 P.

Friesen, H. G. \& Astwood, E. B. (1967). Endocrinology, 80, 278.

van Dyke, H. B., Chow, B. F., Greep, R. O. \& Rothen, A. (1942). J. Pharmacol. 74, 190. 